\title{
ANTIFERTILITY EFFECTS IN RATS OF SOME COMPOUNDS RELATED TO AZASTEROIDS
}

\author{
B. GAIND AND V. S. MATHUR \\ Department of Pharmacology, Postgraduate Institute of Medical Education and Research, \\ Chandigarh, India
}

(Received 24th May 1971)

\begin{abstract}
Summary. Eleven compounds, related to azasteroids, at a dose of 20 $\mathrm{mg} / \mathrm{kg}$ body weight have been screened for antifertility effect in rats when given orally from Days 1 to 7 of pregnancy. An antifertility effect was observed in ten out of thirteen animals with 5-[(2-chlorobenzylidine) -amino]-isoquinoline.
\end{abstract}

Azasteroids have been reported to possess antifertility and antiandrogenic activities (Saksena \& Chaudhury 1969, 1970). These are steroids in which nitrogen forms an integral part of the nucleus (Shoppee, Killick \& Kruger, 1962). In the present study, a series of eleven compounds related to azasteroids have been screened for possible antifertility activity.

The technique followed was basically the same as that described by Saksena \& Chaudhury (1969). Female rats of known fertility belonging to the Charles Foster Strain were used. Every evening the vaginal smears were examined and those females which were in pro-oestrus or early oestrus were kept overnight with males of proven fertility. The presence of thick clumps of spermatozoa in the vaginal smear the following morning was taken to indicate Day 1 of pregnancy for that particular rat. The compounds to be tested were given orally from Days 1 to 7 of pregnancy, the daily dose being $20 \mathrm{mg} / \mathrm{kg}$ in an alcoholic suspension. The controls received the vehicle only. Laparotomy was performed on Day 10 and the number of implants were recorded. The results obtained are presented in Table 1.

Out of this series, the most encouraging results were obtained with $5-[(2-$ chlorobenzylidine)-amino]-isoquinoline. An antifertility effect was seen in ten out of thirteen animals. The mean number of implants was also markedly reduced. These compounds did not show any toxic effects at the dose administered.

Further work is in progress on 5-[(2-chlorobenzylidine)-amino]-isoquinoline, 4[(2-chlorobenzylidine)-amino]-thianaphthene, 4-keto-4,5,6,7-tetrahydro-thianaphthene and 4-keto-4,5,6,7-thianaphthene oxime. Effects at higher doses are being studied, the mechanism of action (blasto-cystotoxic, anti-implantation or early abortifacient) and also the effects of these compounds in another species. 
TABLE 1

EFFECT OF CERTAIN ORALLY ADMINISTERED COMPOUNDS RELATED TO AZASTEROIDS ON IMPLANTATION IN RATS

\begin{tabular}{|c|c|c|c|}
\hline Compounds & $\begin{array}{c}\text { No. of rats } \\
\text { pregnant/ } \\
\text { treated }\end{array}$ & $\begin{array}{l}\text { Percentage } \\
\text { reduction in } \\
\text { pregnancies }\end{array}$ & $\begin{array}{c}\text { No. of implants } \\
\text { in individual } \\
\text { rats }\end{array}$ \\
\hline Controls-vehicle only & $10 / 10$ & $0 \cdot 0$ & $\begin{array}{l}9,9,11,6,7,9, \\
10,5,8,7\end{array}$ \\
\hline 1. 3-deoxy-13-aza-15-thia-18-nor-homo(D)-equilenin & $5 / 5$ & $0 \cdot 0$ & $7,10,12,9,10$ \\
\hline 2. 4-carbethoxy-1,2-dihydro benz(f)isoquinoline & $5 / 5$ & 0.0 & $8,6,8,6,8$ \\
\hline $\begin{array}{l}\text { 3. 7,8,9,10-tetrahydro-7-semicarbazone- benzo(c) } \\
\text { phenanthridine }\end{array}$ & $4 / 5$ & $20 \cdot 0$ & $10,8,7,5$ \\
\hline $\begin{array}{l}\text { 4. } 7,8,9,10 \text {-tetrahydro- } 7 \beta \text {-hydroxy-7 } \alpha \text {-acetylonobenzo } \\
\text { (c) phenanthridine }\end{array}$ & $5 / 5$ & $0 \cdot 0$ & $2,9,8,10,5$ \\
\hline 5. 4-[(2-chlorobenzylidine)-amino]-thianaphthene & $3 / 5$ & $40 \cdot 0$ & $4,5,2$ \\
\hline 6. Thiopheno $(3,2-c)$ phenanthridine & $5 / 5$ & $0 \cdot 0$ & $2,6,9,2,10$ \\
\hline 7. 4-keto-4,5,6,7-tetrahydro-thianaphthene oxime & $3 / 5$ & $40 \cdot 0$ & $3,8,5$ \\
\hline 8. 5-[(2-chlorobenzylidine)-amino]-quinoline & $4 / 5$ & $20 \cdot 0$ & $6,6,3,3$ \\
\hline 9. 4-keto-4,5,6,7-tetrahydro-thianaphthene & $2 / 4$ & $50 \cdot 0$ & 3,6 \\
\hline 10. 4-[(2-chlorobenzyl)-amino]-thianaphthene & $4 / 6$ & $33 \cdot 0$ & $8,9,5,5$ \\
\hline 11. 5-[(2-chlorobenzylidine $)$-amino $]$-isoquinoline & $3 / 13$ & $77 \cdot 0$ & $6,4,4$ \\
\hline
\end{tabular}

The compounds were fed from Day 1 to Day 7 of pregnancy at a dose of $20 \mathrm{mg} / \mathrm{kg}$ body weight.

The compounds related to azasteroids were synthesized by $\mathrm{Dr}$ S. V. Kessar of the Department of Chemistry, Panjab University, Chandigarh. The project has been financed in part by a grant made by the United States Department of Agriculture, Agricultural Research Services, under PL 480.

\section{REFERENCES}

Saksena, S. K. \& Chaudhury, R. R. (1969) Effect on orally administered azasteroids on implantation in rats. F. Reprod. Fert. 19, 177.

Saksena, S. K. \& Chaudhury, R. R. (1970) Anti-androgenic activity of 7,8,9,10-tetrahydro-7-oxobenzo(c) phenanthridine ( $\left.A_{11}-I V\right)$ on immature, castrated, male rats. F. Reprod. Fert. $21,559$.

Shoppee, G. W., Killick, R. W. \& (in part) Kruger, G. (1962) Azasteroids, Part IV. 3-Aza-5 $\alpha$ and-5 $\beta$-cholostane, 4-Aza-5 $\alpha$-and-5 $\beta$-cholostane, and related compounds. 7. chem. Soc. ii, 2275. 